\title{
A dicta do frade Pregador Egídio de Ferrara para a consulta sobre a pobreza de Cristo e dos apóstolos (1322)
}

\author{
Luiz Otávio Carneiro Fleck ${ }^{1}$
}

\begin{abstract}
Resumo: Este texto tem como tema as contendas sobre a pobreza de Cristo e dos apóstolos que atravessaram o papado de João XXII. A hipótese é que essas disputas também afetaram os frades da Ordem dos Pregadores, os quais entraram em conflito entre si em função de divergências acerca do modelo de pobreza da vida apostólica e do lugar do voto de pobreza na vida religiosa. O objetivo do texto é propor caminhos para a comprovação dessa hipótese por meio da teologia desenvolvida pelos frades Pregadores. Primeiro, a partir das atas dos Capítulos Gerais é demonstrada a possibilidade de Pregadores terem se associado aos frades Espirituais. Segundo, foi transcrita e analisada a resposta do frade Egídio de Ferrara para a comissão de 1322 sobre a pobreza de Cristo e dos apóstolos. Foi possível identificar que os conceitos de pecunia, dominium e proprietas podem ser importantes chaves de leitura da documentação administrativa e teológica.
\end{abstract}

Palavras-chave: BAV, Cod. Vat. lat. 3740; Ordem dos Pregadores; voto de pobreza.

\section{The dicta of the friar Preacher Aegidius Ferrariensis for the consultation on the poverty of Christ and the apostles (1322)}

\begin{abstract}
This paper focuses on the disputes over the poverty of Christ and the apostles during John XXII's pontificate. The hypothesis is that these disputes also affected the friars of the Order of Preachers, who quarreled amongst themselves due to divergences over the poverty model of apostolic life, as well as the place of the poverty vow in religious life. The aim of this paper is to propound ways of proving this hypothesis through the theology developed by the Preachers. First, an analysis of the Acts of General Chapters was made, which demonstrated the possibility of a significant number of Preachers associating themselves with the Spiritual friars. Second, Friar Aegidius Ferrariensis' response to the commission of 1322 on the poverty of Christ and the apostles was transcribed and analyzed. Through these procedures, it was possible to identify that the concepts of pecunia, dominium and proprietas may be important concepts for reading the administrative and theological documentation under investigation.
\end{abstract}

Keywords: BAV, Cod. Vat. lat. 3740; Order of Preachers; vow of poverty.

\section{La dicta del fraile Predicador Aegidius Ferrariensis para la Consulta sobre la Pobreza de Cristo y los apóstoles}

Resumen: Este texto tiene como tema los debates sobre la pobreza de Cristo y los apóstoles que cruzaron el papado de Juan XXII. Se presume que estas disputas también afectaron a los frailes de la Orden de Predicadores, quienes se

\footnotetext{
${ }^{1}$ Doutorando em História pela Universidade Federal do Rio Grande do Sul, UFGRS. Mestre em História pela Universidade Federal do Rio Grande do Sul, UFGRS. Graduado em História pela Universidade Federal do Rio Grande do Sul, UFGRS.
} 
enfrentaron entre sí por desacuerdos sobre el modelo de pobreza de la vida apostólica y el lugar del voto de pobreza en la vida religiosa. El propósito del texto es proponer formas de probar esta hipótesis a través de la teología desarrollada por los frailes Predicadores. Primero, a partir de las minutas de los Capítulos Generales se demuestra la posibilidad de que los Predicadores se hayan asociado con los frailes Espirituales. Segundo, se transcribió y analizó la respuesta de fray Aegidius Ferrariensis a la Comisión de Pobreza de Cristo y los Apóstoles de 1322. Fue posible identificar que los conceptos de pecunia, dominium y proprietas pueden ser claves de lectura importantes de la documentación administrativa y teológica.

Palabras clave: BAV, Cod. Vat lat. 3740; Orden de Predicadores; voto de pobreza.

\section{Introdução}

No ano de 1322 o papa João XXII realizou uma comissão para obter resposta à questão: "Se é herético afirmar que Cristo e os apóstolos não possuíram nada individualmente ou em comum?" (SPIERS, 1995, p. 91; NOLD, 2012, p. 646). Respostas foram obtidas de aproximadamente sessenta membros da Igreja. Entre os participantes estavam cardeais, bispos e mestres de teologia. A consulta e sua questão tinham como pano de fundo as disputas entre o papado de Avinhão e grupos de frades da Ordem dos Frades Menores (OFM), mais conhecidos como Espirituais, acerca do modelo de pobreza e de perfeição legado pela vida apostólica (NOLD, 2012, p. 646; PIRON, 2012, p. 381). Essas contendas tinham implicações políticas mais amplas na afirmação da plenitudo potestatis (plenitude do poder) do papado. Ao longo da década de 1320, intensificaram-se os conflitos entre João XXII e Luís da Bavária, imperador do Sacro Império Romano Germânico, pela influência e controle de cidades na Itália. Os Espirituais, que buscaram proteção no imperador, e a defesa da pobreza absoluta de Cristo e dos apóstolos forneciam argumentos para deslegitimar as pretensões de poder temporal do papado (SILVA, 2015, p. 76-78 e 84-90).

Sobre esse contexto de conflitos, pouca atenção foi dada para a participação dos frades da Ordem dos Pregadores (OP) nas discussões e disputas acerca da pobreza. Como aponta Patrick Nold os frades Pregadores ${ }^{2}$, geralmente, são descritos como aliados do papado e com grande poder de influência sobre esse, porém as particularidades das concepções destes frades sobre a pobreza não são consideradas (NOLD, 2012, p. 646-647).

\footnotetext{
${ }^{2}$ Ao utilizar "Pregadores" com o "p" maiúsculo está sendo feito referência a identidade dos frades como membros da Ordem dos Pregadores.
} 
Aqui é proposta a seguinte hipótese: a resolução da questão sobre a pobreza de Cristo e dos apóstolos também afetava os frades Pregadores e a OP. A Ordem não era um bloco uníssono e os frades dirigentes tiveram de enfrentar grupos de Pregadores que expressavam opiniões semelhantes às dos Espirituais da OFM. Portanto, frades da OP disputaram e divergiram entre si acerca de concepções sobre a pobreza e o lugar que o voto tinha na vida religiosa dos Pregadores. O objetivo é propor caminhos e chaves de leitura para investigar a hipótese na documentação administrativa da OP e na produção teológica dos frades.

O texto está dividido em duas seções. Na primeira a partir das atas dos Capítulos Gerais (CGs) são apresentados indícios de conflitos internos na OP acerca da questão da pobreza. Também é discutida a participação dos frades Pregadores na comissão de 1322 sobre a pobreza de Cristo e dos apóstolos. A segunda seção é dedicada a análise da resposta de um frade Pregador para a comissão da pobreza, obtidas no manuscrito da Biblioteca Apostólica do Vaticano, Códice Vaticanus latinus 3740: a dicta (declaração) de Egídio de Ferrara. Na conclusão são propostos os conceitos de pecunia, dominium e proprietas como possíveis chaves de leitura para a documentação.

\section{A Ordem dos Pregadores e as contendas acerca da pobreza de Cristo e dos apóstolos}

\subsection{Atas dos Capítulos Gerais (1321-1330)}

O Capítulo Geral (CG) era a instância de maior autoridade na OP, sua ocorrência era anual e tinha o poder de alterar as Constituições e propor a interpretação das leis (FORTES, 2011, p. 40; VARGAS, 2011, p. 86 e 87). Da mesma forma buscava-se combater "desvios comportamentais" dos frades por meio da descrição, delimitação e normatização jurídica da conduta dos Pregadores (GELTNER, 2010, p. 50; VARGAS, 2011, p. 129). Dos CGs é possível ter acesso às atas que, apesar de não conterem uma descrição detalhada da reunião, registram as regulamentações votadas pelo mestre geral e pelos definidores. Essa documentação pode dar indícios acerca de possíveis dissensos entre os Pregadores na interpretação do voto de pobreza e do lugar desse na vida religiosa dos frades, entre outros possíveis conflitos.

Entre os anos de 1321 e de 1330 é possível identificar nas atas dos CGs, sobretudo na seção dos avisos e ordenações (admoniciones et ordinaciones), indícios do 
envolvimento da Ordem e de frades individuais com as contendas da pobreza e o conflito entre João XXII e Luís da Bavária. Em Florença (1321), uma carta do mestre geral e dos definidores narra a realização de uma investigação sobre frades da província Romana, associados aos Espirituais da OFM, em denúncias, por serem considerados "de vida singular". Os dirigentes gerais determinaram como falsa a acusação, porém foram propostas medidas para evitar que viessem a se desenvolver grupos de Pregadores "de vida singular" ou que os mesmos se associassem a grupos como os Espirituais (MOPH IV, 1899, p. 137) $)^{3}$.

Apesar de em 1321 os dirigentes gerais afirmarem não ter encontrado frades com "de vida singular", os mesmos voltaram a figurar na ata do CG de Perpignan (1327). No início da seção dos "avisos e ordenações" (admoniciones et ordinaciones) há um conjunto de sete regulamentações, seguidas da orientação de que todas estavam endossadas pela autoridade do papa e deveriam ser inscritas no final das Constituições (MOPH IV, 1899, p. $170)^{4}$. Dois pontos se destacam neste conjunto de regulamentações. Primeiro, era um procedimento legislativo incomum entre os frades Pregadores (uma regulamentação deveria ser votada três vezes para ser inscrita nas Constituições $^{5}$ ), o que demonstra uma certa urgência dos frades dirigentes em resolver pontos relativos ao comportamento dos Pregadores. Segundo, entre os problemas que demandavam resolução as duas primeiras regulamentações abordam questões que podem ser relacionadas às contendas sobre a pobreza de Cristo e dos apóstolos: (a) seriam punidos com cárcere os frades que difamassem o papa ou seus processos apostólicos em público e com pena por falta mais grave caso o fizessem em privado (MOPH IV, 1899, p. 168 e 169) ${ }^{6}$; (b) são previstas

\footnotetext{
3 “(...) auditis et eciam receptis in scriptis delacionibus contra fratres aliquos de Romana provincia, qui spirituales ab aliquibus vocabantur, diligenti prius inquisicione premissa, examinando delatos per sentenciam excommunicacionis et per preceptum et eciam iuramentum, non invenimus in predictis esse probatum contra eos aliquid contra fidem seu eciam bonos mores, nec eciam in eis invenimus singularitatem vite fundatam in aliqua heresi vel errore. (...)".

4 "Sciant omnes fratres ordinis nostri, quod omnes ordinaciones predicte vim constitucionum nostrarum habent, auctoritate domini nostri summi pontificis, non obstante, quod non habent, nisi presens capitulum generale et omnes in fine libri constitucionum nostrarum integre conscribantur."

${ }_{5}$ Para mais ver: FORTES, C. C. Societas studii: a construção da identidade institucional e os estudos entre os frades pregadores no século XIII. Tese (Doutorado), 370 f. UFF/ICHF, 2011. Disponível em: < http://www.historia.uff.br/stricto/td/1344.pdf>; GALBRAITH, G. R. The Constitution of the Dominican Order, 1216 to 1360. Manchester: Manchester University Press, 1925, 1. ed. e VARGAS, M. Taming a Brood of Vipers: Conflict and Change in Fourteenth-Century Dominican Convents. Leiden; Boston: Brill, 2011.

6 "Quicumque in publica predicacione vel in communi coram secularium multitudine ullo tempore summum pontificem diffamaverit vel ipsius processus vel facta vel irreverenciam notabilem fecerit, carcerali custodie mancipetur, nec inde liberetur nisi per capitulum generale et cogatur, si commode fieri poterit, in publico revocare. Qui autem in privato, postquam per testes legitimos constiterit vel iudicialiter confessus fuerit, pena
} 
punições, agravadas em caso de reincidência, chegando até a prisão, para frades " de vida singular" (MOPH IV, 1899, p. 169) ${ }^{7}$. Em (a) é possível perceber que alguns Pregadores tinham críticas aos processos apostólicos de João XXII, entre os quais predominavam, no período, os processos contra os Espirituais da OFM. Da mesma forma em (b) novamente são mencionados frades "de vida singular", os quais iam contra o "modo de viver comum aprovado pela Ordem". Ou seja, mesmo com a negativa da investigação de 1321, sobre ligações entre Pregadores e Espirituais, frades com "de vida singular" eram um problema para o mestre geral e os definidores em 1327. Então, os frades dirigentes buscavam normatizar e combater grupos de Pregadores com uma conduta semelhante à dos Espirituais da OFM, o que poderia implicar em diferentes interpretações acerca do modelo de vida apostólico e do lugar da pobreza na vida religiosa.

No ano seguinte, no CG de Toulouse (1328), na seção dos “avisos e ordenações", é preceituado aos frades que não mantivessem relações com Luís da Bavária, “(..) inimigo e perseguidor da Santa Igreja Romana e pela mesma condenado como herege (..)”, e com seus apoiadores heréticos. Os Pregadores que fizessem o contrário seriam punidos com prisão. Também deveriam divulgar, em sua pregação aos laicos, as novidades dos processos apostólicos contra Luís (MOPH IV, 1899, p. 178 e 179) ${ }^{8}$. Portanto, havia uma preocupação quanto a possíveis conexões entre os frades Pregadores e o imperador do Sacro Império Romano Germânico e, por consequência, com os Espirituais da OFM.

gravioris culpe puniatur, et nisi per provinciale capitulum vel per priorem provincialem de maturo consilio discretorum cum eo minime dispensetur. Idem fiat de falso accusatore vel teste legitime convicto vel iudicialiter confessato in materia supradicta; prelati vero, qui in corrigendo huiusmodi transgressores inventi fuerint negligentes, per generale vel provinciale capitulum in penam a suis officiis absolvantur et preter hoc penis aliis gravius puniantur."

7 "Quicumque in nostro ordine inventi fuerint singularem vitam quocumque modo viciosam ducentes et contra communem modum vivendi diu ab ordine approbatum, primo admoneantur, et si admoniti correcti non fuerint, separentur et in diversis conventibus ponantur; et si in eodem persistant, per priorem provincialem vel provinciale capitulum carcerali custodie mancipentur."

8 “Cum ex eo, quod illi, qui debent esse ceterorum exemplaria in actibus virtuosis exorbitent ab illius itinere, quem dominus ducem et principem aliorum in tota universali ecclesia instituit, sequatur in grege dominico perniciosus error, scandalosa imitacio ac dampnatum precipicium plurimorum, mandamus et omni districtione, qua possumus, imponimus fratribus universis, nec non et magister ordinis, in virtute spiritus sancti et sancte obediencie, precipit fratribus universis, de diffinitorum consilio et assensu, quod Ludovicum quondam ducem Bavarie, hostem et persecutorem sacrosancte Romane ecclesie ac per eamdem tanquam hereticum condempnatum nec non et omnes alios fautores eiusdem tanquam hereticos condempnatos vitent, ac interdictum occasione dicti perfidi Bavari per sanctam Romanam ecclesiam positum inviolabiliter servent, nec eidem Bavaro vel suis predictis fautoribus quocumque modo prebeant consilium, auxilium vel favorem. Si qui autem contrarium inventi fuerint facientes, pena carceris, ad quam ex nunc pro tunc eos adiudicamus, inviolabiliter puniri volumus, et mandamus eisdem mandatis et imposicionibus, quibus supra iniungentes, quod fratres in suis predicacionibus iuxta formam mandati apostolici processus noviter factos contra dictum Bavarum cum omni diligencia studeant publicare." 
Dois anos depois, nas cláusulas penitenciais do CG de Utrecht (1330) está registrada a seguinte decisão:

\begin{abstract}
Declaramos a todos os frades, que todos e cada um dos frades, os quais de alguma forma deram ajuda ou conselho para Luís, antes duque da Bavária, Miguel de Cesena, antes ministro geral da Ordem dos Frades Menores, e Pedro de Corbaria, e aos cúmplices deles condenados [como] heréticos e cismáticos pela Santa Igreja Romana, que [aqueles frades que] antes foram sentenciados à prisão e por escrito condenados a penas nas prisões pelo respeitado pai, o mestre geral, e a dita condenação, o dito mestre, renova e promulga de forma pública no presente Capítulo (MOPH IV, 1899, p. 197. Adaptado) ${ }^{9}$.
\end{abstract}

Ou seja, são apontadas condenações à prisão anteriormente feitas pelo mestre geral Barnaba Cagnoli a frades por auxiliarem e manterem contato com Luís da Bavária e dois frades Menores envolvidos com os Espirituais, Miguel de Cesena e Pedro de Corbaria. Os "cúmplices heréticos e cismáticos" aos quais a regulamentação faz referência, provavelmente, são os frades Espirituais. Em 1328, foi colocado um veto, por preceito, a estas relações dos frades Pregadores com adversários do papado. Pelo que indica a cláusula penitencial de 1330, alguns Pregadores já haviam sido punidos pela quebra do preceito, sendo renovadas e ordenadas novas condenações ao cárcere por envolvimento com Luís e com os Espirituais. Entre esses frades provavelmente estava Bonifácio Donoratico de Pisa, frade Pregador que foi cardeal de Nicolau V.

$\mathrm{Na}$ ata de 1330, também, está anexado um documento intitulado "Instrumentos públicos de condenação fulminante de Luís da Bavária, Miguel de Cesena e Pedro de Corbaria", no qual são resumidas as bulas papais Nuper videlicet, Dudum contra Michaelem, Quia vir reprobus e Adversus hominem. Entre essas bulas interessa a atenção dada à Quia vir reprobus. Antes de elencar os erros que levaram à condenação de Miguel, o mestre geral pediu para que esses fossem de conhecimento de todos os conventos e frades da $\mathrm{OP}^{10}$. Dos seis erros apontados, os três primeiros dizem respeito à relação com bens e ao modelo apostólico de pobreza:

$\S$ O primeiro, que no uso de bens consumíveis é possível separar o usufruto da propriedade ou domínio. § O segundo, que no uso de bens consumíveis é

\footnotetext{
${ }^{9}$ Tradução Livre: "Denunciamus fratribus universis, quod omnes et singuli fratres, qui quocumque modo Ludovico, quondam duci Bavarie, Michaeli de Cesena, quondam generali ministro ordinis fratrum minorum, et Petro de Corbaria, et complicibus eorum hereticis dampnatis ac scismaticis per sanctam Romanam ecclesiam adheserint aut eisdem prestiterint auxilium vel consilium, dudum per reverendum patrem magistrum ordinis fuerint sentencialiter et in scriptis carceri penisque carceralibus condempnati, dictamque condempnacionem dictus magister in presenti capitulo renovavit et publice promulgavit (...)".

10 "Quem quidem libellum mandat dictus pater per magistrum ordinis predicatorum in ipsorum generali capitulo publicari et communicari conventibus et fratribus ordinis antedicti."
} 
possível separar o direito de usufruto do direito de usar. $\S$ O terceiro, que Cristo e os apóstolos não tiveram nenhum domínio próprio ou comum de todos os bens e também nem mesmo [tiveram] o direito de usar em qualquer bem, pois esses [os bens] se opõem à perfeição evangélica (MOPH IV, 1899, p. 205. Adaptado) ${ }^{11}$.

Todos os frades deveriam estar cientes de como o modelo de pobreza apostólica não deveria ser interpretado e posto em prática, sendo afirmada a relação de propriedade com os bens que se utilizava. Esta relação existia pelo direito e de forma alguma era contrária à perfeição da vida religiosa. Portanto, a partir das regulamentações e do conteúdo dos CGs de 1321, 1327, 1328 e 1330 é possível afirmar que grupos de frades Pregadores que mantinham relações com Luís da Bavária, com Miguel de Cesena, com Pedro de Corbaria e com Espirituais da OFM foram punidos pelos dirigentes da OP. Da mesma forma, a atuação de frades "de vida singular" que se diferenciavam dos demais Pregadores, e possivelmente uma determinada concepção do modelo apostólico de pobreza, foi combatida pela descrição na legislação da Ordem.

As evidências obtidas na documentação administrativa tornam plausível a hipótese de que grupos de frades Pregadores, inseridos em um contexto de disputas acerca da definição do modelo de vida apostólico, possuíam conflitos em termos das concepções acerca do voto de pobreza e de seu lugar na vida religiosa. Para identificar estas diferenças são analisadas interpretações de frades individuais da OP sobre o modelo de pobreza apostólica.

\subsection{A comissão de 1322 e o manuscrito BAV, Cod. Vat lat. 3740}

Para analisar a forma como alguns frades Pregadores estavam pensando o modelo de pobreza para a vida religiosa uma das fontes é o manuscrito MS BAV, Cod. Vat. lat. 3740. Neste códice estão reunidas as respostas para a consulta de 1322 sobre a pobreza de Cristo e dos apóstolos, sendo a cópia que chegou às mãos de João XXII. Como aponta Sylvan Piron, a realização de consultas, com grande participação de teólogos, era um modus operandi do papado de João XXII na legitimação das decisões das bulas pontifícias (PIRON, 2011, p. 381 e 382). Em 1322, as respostas de teólogos e canonistas sobre o

\footnotetext{
11 Tradução livre: "§ Primus est, quod in rebus usu consumptibilibus ususfructus potest a proprietate seu dominio separari. § Secundus est, quod in rebus usu consumptibilibus potest ususfructus iustus separari a iure utendi. $\S$ Tercius est, quod Christus et apostoli nullius rei omnino habuerunt dominium in proprio vel communi nec eciam in re aliqua ius utendi, quia hec evangelice perfectioni repugnarent”.
} 
modelo de pobreza apostólica serviram de base para a preparação da bula Ad conditorem canonum (1322), com a qual foram revogadas disposições da Exiit qui Seminat de Nicolau III (1279) atacando, sobretudo, a fundamentação jurídica do "simples uso de fato". E da bula Cum inter nonnullos (1323), com a qual foi condenada como herética a afirmação de que Cristo e os apóstolos não possuíram nada individualmente ou em comum (NOLD, 2011, p. 646).

O MS BAV, Cod. Vat. lat. 3740 é um relatório, que possui textos produzidos em espaços de tempo distintos (NOLD, 2003, p. 41 e 42). O códice é dividido em cinco partes de acordo com a condição do autor dentro da Igreja e a natureza da opinião sobre a pobreza (NOLD, 2003, p. 34). A maior parte dos textos é oriunda do consistório realizado em 26 de março de 1322, do qual participaram cerca de sessenta membros da Igreja, entre cardeais, prelados e mestres de teologia. A forma como os textos estão agrupados no códice é apresentada nos primeiros fólios por meio de uma lista (fos. 1r e 2r). Na primeira parte e na segunda estão os textos de frades Menores favoráveis à pobreza absoluta de Cristo e dos Apóstolos. Os textos da primeira parte são identificados como dicta (declarações) e são opiniões escritas após o consistório de 26 de março (NOLD, 2003, p. 40). A segunda parte, conforme Patrick Nold, é excepcional dentro do manuscrito, sendo os textos oriundos da anotação de declarações orais de frades Menores em um consistório particular, intituladas Compendiose Resumptiones Dictorum (NOLD, 2003, p. 41 e 42). A partir da terceira parte, na qual estão as respostas de cardeais, seguem as opiniões contrárias a afirmação da pobreza absoluta de Cristo. Na quarta estão as respostas de prelados e na quinta de mestres de teologia. Os textos destas partes são intitulados dicta, responsiones, consilium e rationes et allegationes (NOLD, 2003, p. 41). Segundo Nold, alguns participantes retornaram suas opiniões ao papa logo após a consulta, produzindo textos curtos, outros levaram mais tempo, e produziram textos mais longos e complexos. Da mesma forma, como no caso do Pregador João de Nápoles, foram enviadas mais de uma resposta (NOLD, 2003, p. 41).

A parte escrita inicia no fólio 3ra, com a resposta do cardeal Vital du Four, e finaliza no fólio 261v com um "rascunho" da bula Cum inter nonnullos que provavelmente, pela letra, é de autoria de João XXII. O códice é composto de 261 fólios, sendo a dimensão da parte textual de $250 \times 350 \mathrm{~mm}$. Cada fólio possui 33 linhas, com o texto dividido em duas colunas (Figura 1). Antes de cada resposta é identificado o nome e/ou condição do autor. A primeira letra de cada texto é destacada, ocupando duas linhas 
do fólio e alternando-se entre azul e vermelho (Figura 2). O restante do texto é escrito em tinta preta, desbotada em muitas partes adquirindo uma coloração marrom. As letras são bem desenhadas em função do manuscrito ter sido produzido para o uso direto do pontífice, o que facilita a leitura. O número de cada fólio é indicado no canto superior direito do recto em tinta preta (Figura 3).

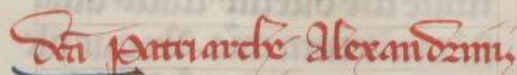

II Dauctuonem quaque

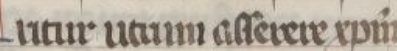

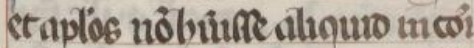

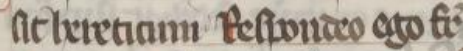
egroure prianta alcranomi Q ario levenann ce-erdolux moucue me auctortater ma once all egate pet angin fact pilacis ot alios angrios metho logia altotas piclatas out tup Ix coram ono nio ftuno pont fire fime loath- precture mem oucunt auctortates cumge

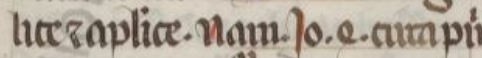
apum flc otat. orletpult cuis abietme in cautatem utetio encient. et. 10.13 - atta them Ouaiputabie nalaulos ba tront nutas etongue mutte the

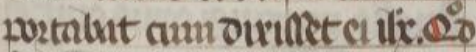
facre fac atule nó outelt cunc ouc ovuo fint nob araic fecthi

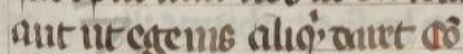

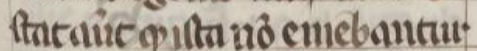

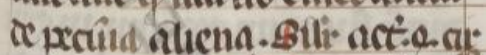
mfinem ficoler. Amurill:cap

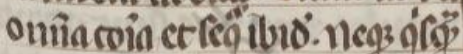
egtenectutmentlos. oustout cinoffellozs aqto2 aut avmo2

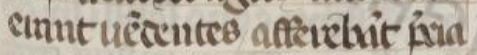
conquenendát et moncbant aì pare aplow oututuit auten fintulue sut augs opuserat. (1)

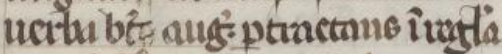

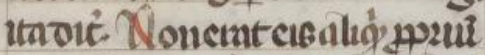
teoctrit en otria coin. vit meos

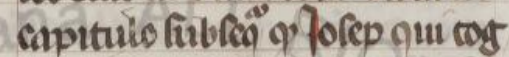
noumnatue ç trrenalate ab aplis ailktet ngtui ucudont ai z attu he bicuum ct potutenu pare aplo?

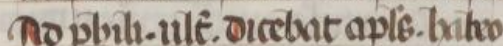
omiarlibunto-otatglö. Iattw onvia que mifilhe un-2vet diftur. Aonem ctian ut orat - jo. ienan. feoletuit no prifatone; etprenor

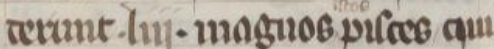
cunn tentr ceite non en finctum reth. Conttat anit of fluzectedu

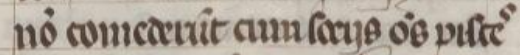

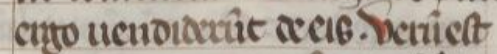
Q aliour orant xpm ct aploo

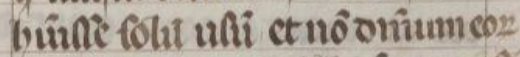
auclíbunt auro villa wône uré

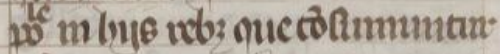
ufit ut m bane buno et doruma

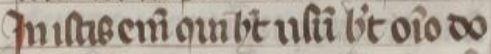

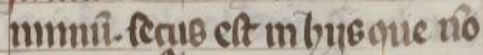
cônumunt vicu ut m romo reou

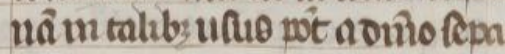
tmat.

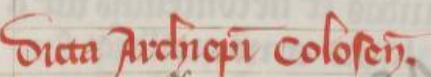
ucut uai allevere xpins aplos nóbuntue alió mat 
Figura 1 - Dicta de Egídio de Ferrara (fólio 152r).

Fonte: Biblioteca do Vaticano.

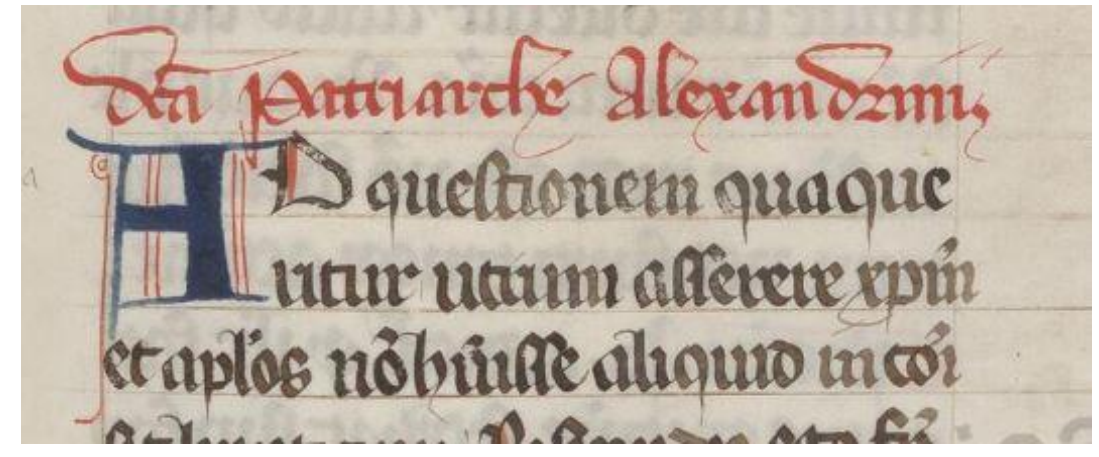

Figura 2 - Título e letra capitular (fólio 152rb).

Fonte: Biblioteca do Vaticano.

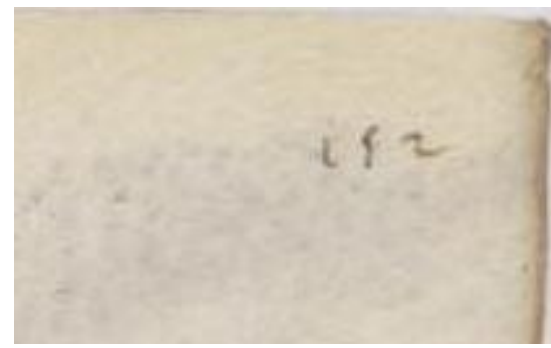

Figura 3 - Número do fólio (fólio 152r).

Fonte: Biblioteca do Vaticano.

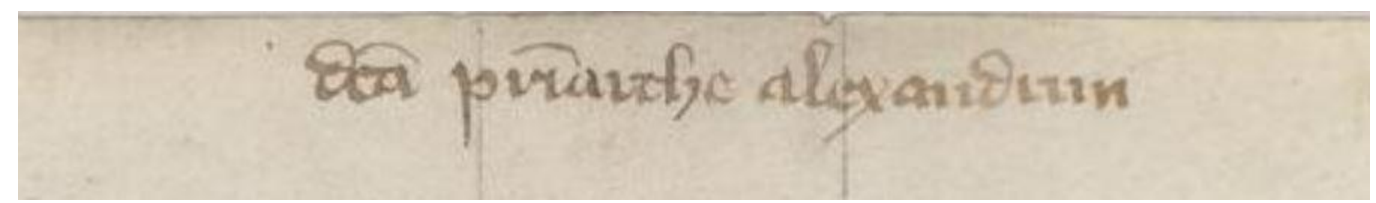

Figura 4 - Anotação de João XXII (fólio 152r).

Fonte: Biblioteca do Vaticano.

Ao longo do manuscrito é possível identificar intervenções de João XXII, nas quais o papa repete e destaca pontos de algumas respostas (Figura 4). O papa também reescreve o nome do autor da resposta, o que indica a leitura da mesma (NOLD, 2012. p. 650 e 651). Aqui interessa sobretudo que no MS BAV, Cod. Vat. lat. 3740 estão presentes as "opiniões 
oficiais" ${ }^{12}$ de sete frades Pregadores sobre a pobreza de Cristo e dos Apóstolos. O conteúdo das respostas desses frades podem dar indícios sobre interpretações conflitantes acerca do modelo de pobreza legado pela vida apostólica e o lugar do voto de pobreza na vida religiosa dos Pregadores. Para a análise inicial foi selecionada a resposta de Egídio de Ferrara presente no fólio $152 \mathrm{r}^{13}$ do manuscrito.

\section{A resposta de Egídio de Ferrara à comissão de 1322 sobre a pobreza de Cristo e dos apóstolos}

Sobre o local e data de nascimento de Egídio de Ferrara não foram obtidas informações. É provável que fosse oriundo da cidade de Ferrara. A data de entrada do frade para a OP e o convento no qual fez sua profissão são desconhecidos. Da mesma forma, não foram encontradas informações sobre os estudos de Egídio. Ao longo de sua vida, Egídio ocupou cargos na hierarquia eclesiástica. Em maio de 1296 foi confirmado como Patriarca de Grado na Itália e em outubro de 1311 como Patriarca de Alexandria no Egito. No ano 1322 é provável que estivesse em Avinhão, onde participou da comissão sobre a pobreza de Cristo e dos apóstolos. Ao que tudo indica Egídio não retornou para Alexandria, morrendo em Tarascon na França, no dia 06 de junho de $1323^{14}$.

A dicta de Egídio de Ferrara é curta, ocupando o recto do fólio 152, sendo elencadas poucas autoridades, o que indica que o texto foi produzido e enviado logo após o consistório de 26 de março. A resposta pode ser dividida em três partes. O frade inicia respondendo diretamente à pergunta "se é herético afirmar que Cristo e os apóstolos não possuíram nada individualmente ou em comum?”: "Eu, frade Egídio, Patriarca de Alexandria, respondo que acredito ser [tal afirmação] herética.” (BAV, Cod. Vat. lat. 3740,

\footnotetext{
${ }^{12}$ No BAV, Cod. Vat. lat. 3740 estão presentes as respostas de Hervaeus Natalis (mestre geral de 1318 até 1323), Agostinho Kazotic, Domingos de Grima, Durando de São Porçiano, Egídio de Ferrara, João de Nápoles e Tiago Fusignano. Outros dois frades redigiram respostas para a consulta de 1322: Nicolau Trevet e Raimundo Béquin. Entretanto, as dictae de ambos não se encontram no manuscrito da Biblioteca Apostólica do Vaticano.

${ }^{13}$ A escolha se deu por essa ser a menor resposta dentre os frades Pregadores que participaram da comissão, e por isso um bom caminho para o primeiro contato com o manuscrito. Para realizar a transcrição do fólio $152 \mathrm{r}$ o texto foi comparado com os fólios 125v e 126r do códice da Biblioteca Nacional da Espanha Mss. 4165, cópia do século XV de um manuscrito que foi copiado do MS BAV, Cod. Vat. lat. 3740. O BNE Mss. 4165 está disponível no acervo digital da Biblioteca Nacional da Espanha, no seguinte endereço: <http://bdhrd.bne.es/viewer.vm?id=0000134673\&page=1>.

${ }^{14}$ Essas são informações iniciais obtidas acerca da vida de Egídio de Ferrara. Uma pesquisa mais aprofundada será feita ao longo dos próximos anos. O relato biográfico do frade foi obtido em: KAEPPELI, T. (OP). Scriptores Ordinis Praedicatorum Medii Aevi. Roma: Typis Polyglottis Vaticanis, 1954. Volume 1 (A-F). p. 10.
} 
1322, fl. 152ra. Adaptado ${ }^{15}$ Segundo Egídio, sua opinião seguia as respostas de outros participantes da comissão, nas quais baseava a interpretação das autoridades elencadas em seu texto (BAV, Cod. Vat. lat. 3740, 1322, fl. 152ra) ${ }^{16}$.

A resposta do frade é desenvolvida em dois argumentos. Primeiro, são elencados dois capítulos do evangelho de João: capítulo 4, versículo 8, em que os apóstolos são encarregados por Cristo de conseguirem comida na cidade samaritana de Sicar; e o capítulo 13, versículos 27 a 29, trecho no qual é narrado o momento da traição de Judas, dando-se destaque para as bolsas que ele carregava (BAV, Cod. Vat. lat. 3740, 1322, fl. 152ra ${ }^{17}$. A partir destas autoridades Egídio concluí o seguinte: “Quanto a isso é um fato estabelecido que essas [coisas necessárias] não foram adquiridas por meio da moeda de outras pessoas." (BAV, Cod. Vat. lat. 3740, 1322, fl. 152ra. Adaptado) ${ }^{18}$. Isto é, para Egídio os trechos do evangelho de João demonstravam não só que Cristo e os Apóstolos faziam uso de moeda (pecunia) como tinham a propriedade dessa.

Conforme Roberto Lambertini, havia uma tradição dentro da OP na qual, para a imitação de Cristo e dos Apóstolos, o uso moeda pelos frades era proibido apenas in viam (no caminho), isto é, aos que iriam pregar entre os laicos. Ao restante dos Pregadores o uso e a posse de moeda não eram vetados. Essa tradição estava alicerçada tanto na legislação quanto na produção hagiográfica e teológica dos frades Pregadores (LAMBERTINI, 2004, p. 8-15). Ao demonstrar o uso e posse de moeda por Cristo e pelos Apóstolos, Egídio parte de uma forma já consolidada de considerar a relação entre uso de moeda e pobreza na vida religiosa dos Pregadores. Portanto, apesar de não mencionar o ponto da proibição de portar e usar moeda aos frades que pregavam, Egídio considera o uso e posse de moeda como parte integrante do modelo de pobreza legado pela vida apostólica.

No segundo argumento, o frade busca demonstrar que os Apóstolos possuíram bens em comum. Para isso utiliza os versículos 32 a 37 do capítulo 4 dos Atos dos Apóstolos. Este trecho é mobilizado para demonstrar a posse comum dos bens entre os Apóstolos e as pessoas que os seguiam, fazendo com que não existissem necessitados (BAV, Cod. Vat.

\footnotetext{
${ }^{15}$ Tradução livre: "Respondeo ego frater Egidius Patriarcha Alexandrinus quod credo hereticum esse".

16 "Et ad hoc movent me auctoritates et rationes allegate per Magistrum sacri palacii, et alios magistros in theologia, aliosque prelatos qui super hoc coram domino nostro summo pontifice sunt locuti precipue me in ducunt auctoritates evangelicae et apostolicae."

17 "Nam Iohannes 4 (:8) circa principium sic dicitur: Discipuli eius abierant in civitatem ut cibos emerent. Et Iohannes 13 (:27-29) circa finem: Quidam putabant quia loculos habebat Iudas, et ea quae mittebantur portabat, cum dixisset ei Iesus: Quod facis fac citius, quod dixisset eme quae opus sunt nobis ad dictam festum, aut ut egenis aliquid daret. Constat autem quod ista non emebantur de pecunia aliena."

${ }^{18}$ Tradução livre: "Constat autem quod ista non emebantur de pecunia aliena".
} 
lat. 3740,1322 , fl. 152ra-rb) ${ }^{19}$. Para reforçar que em vida os Apóstolos tiveram posse comunitária de bens, o frade utiliza um texto de Agostinho de Hippona (Regula Tertia ou Praeceptum) do qual é destacado um excerto que afirma que os Apóstolos não possuíam nada próprio, mas tudo o que tinham era comunitário (BAV, Cod. Vat. lat. 3740, 1322, fl. $152 \mathrm{rb})^{20}$. Segundo Lambertini, tanto os frades Pregadores quanto os frades Menores buscaram basear seu modelo de vida religiosa no livro dos Atos dos Apóstolos (LAMBERTINI, 2004, p. 6). Egídio, então, busca demonstrar que possuir bens em comum fazia parte do modelo de pobreza da vida apostólica. Também é possível apontar como implicação para esse tipo de argumentação de Egídio a sua experiência como patriarca. $\mathrm{O}$ cargo de patriarca se assemelhava ao do bispo, portanto, implicava a administração e posse de bens temporais.

$\mathrm{Na}$ continuação do argumento, o frade escreve:

Na última carta aos Filipinos (c. 4:18) dizia o apóstolo [Paulo]: "tenho todas as coisas e tenho em abundância", diz a glosa: "tenho todas as coisas que vós trouxestes para mim”. Da mesma forma após a Ascenção diz João naquele evangelho: "Retornaram para a pesca e prenderam 153 peixes grandes, que mesmo sendo tantos não romperam a rede." Quanto a isso é um fato estabelecido que os filhos de Zebedeu não comeram com os companheiros todos os peixes, pois venderam o que concernia a eles (BAV, Cod. Vat. lat. 3740, 1322, fl. 152 rb. Adaptado) $)^{21}$.

Neste trecho, Egídio busca demonstrar a relação de posse dos Apóstolos com os bens por meio da vinculação entre a pessoa e a coisa que se tem. Para isso utiliza uma glosa, aqui identificada como a Glossa Ordinaria ${ }^{22}$, para dar ênfase na relação de propriedade que os Apóstolos tinham com as coisas que utilizavam, pois o "tenho tudo" (habeo omnia) é vinculado à pessoa "eu" que recebe algo (quae misistis mihi). Na

\footnotetext{
19 "Similiter Actus Apostolorum 4 (:32) circa finem sic dicitur: Erant illis scilicet apostolis omnia communia, et sequitur (Actus c.4: 34-35) ibidem, neque quisquam egens erat inter illos, quotquot enim possessores agrorum aut domorum erant vendentes, afferebant pecunia eorum quae vendebant et ponebant ante pedes apostolorum, dividebant autem singulis prout cuique opus erat."

20 "Quae verba beatus Augustinus per tractatus in regula ita dicit: Non erat eis aliquid proprium sed erant eis omnia communia."

${ }^{21}$ Tradução livre: "Ad Philippenses ultimo (c. 4: 18), Dicebat apostolus: habeo omnia abundo, dicit glosa: habeo omnia quae misistis mihi. Post ascensionem etiam ut dicit Iohannes (c. 21:10-11) ibi evangelio: Redierunt ad piscationem et prendiderunt 153 magnos pisces, qui cum tenti essent non est fractum rete. Constat autem quod filii Zebedei non comederunt cum sociis omnes pisces ergo vendiderunt de eis".

22 "Habeo autem omnia [glosa na entrelinha: non quero datum tamen omnia habeo] et abundo, [glosa na entrelinha: non in uno ut in alio egeam sed] repletus sum, ab Epafrodito [glosa na entrelinha: muneribus] que misistis [glosa na entrelinha: mihi]". In: MORARD, M.; GIBIINO, F.; e SORBETS, M.-J. (Eds.) Glosa Ordinaria. Paris: Glossae Scripturae Sacrae-Electonicae (Gloss-E). Sem paginação. Disponível em: <http://gloss-e.irht.cnrs.fr/php/livres-liste.php>.
} 
sequência, a conclusão do argumento Egídio causa confusão, uma vez que ele afirma que os apóstolos Tiago e João não teriam comido todos os 153 peixes com seus companheiros, pois haviam vendido sua parte. Ainda não foi possível determinar como Egídio chega a essa conclusão, é possível que se trate de uma glosa ainda não identificada ${ }^{23}$. Apesar disso, pode-se perceber a proposta de uma relação entre pessoa e objeto, destacada por cada um dos Apóstolos ter sua parte dos peixes e poder fazer o que desejasse com essa. Nesse sentido, no segundo argumento o frade: primeiro, demonstra que os Apóstolos possuíam bens em comum e, para dar ênfase na relação de propriedade, propõe uma relação pessoal entre "coisa" que se "usa" e "quem faz o uso".

Esta vinculação entre "objeto e pessoa” é explorada ao final da resposta:

\begin{abstract}
É fato que alguns disseram que Cristo e os apóstolos tinham apenas o uso, e que [sobre as coisas] não havia domínio deles, o que não é observado por nenhuma razão possível nesses bens que são consumidos com o uso, como no pão, no vinho e na moeda. Então nesses [bens consumíveis] dos quais se tem o uso se tem total domínio, o que é diferente nesses [bens] que não são consumidos pelo uso, como a casa ou o cavalo, uma vez que em tais [bens] o uso pode ser separado do domínio (BAV, Cod. Vat. lat. 3740, 1322, fl. 152rb. Adaptado) ${ }^{24}$.
\end{abstract}

No início do trecho é feita referência à teoria do "simples uso de fato" defendida pelos Espirituais da OFM e sancionada pela bula Exiit qui Seminat de 1279, de Nicolau III. A crítica de Egídio vem no sentido de demonstrar a impossibilidade da existência de um "uso sem direitos de propriedade", reconhecendo a propriedade comunal como parte do modelo de pobreza da vida apostólica, por meio do conceito de dominium (domínio). Para Egídio, o uso sem propriedade era possível apenas em bens não consumíveis, que não se desgastavam. Entretanto, fazer uso de um bem consumível, como alimento ou moeda, era impossível sem relação de propriedade, uma vez que esse perdia sua substância. Nestes bens, era necessário o domínio da "pessoa que usa" sobre o "bem que é usado".

O termo domínio era empregado em diferentes situações e com diversos significados no século XIV, dos quais John Kilcullen destaca quatro: poder de um ser racional sobre seus atos; poder de governar; poder sobre as coisas (proprietas); e poder que Adão e Eva tinham no Estado de Inocência sobre as outras criaturas (KILCULLEN, 2011).

\footnotetext{
${ }^{23}$ Agradeço ao Prof. Dr. Roberto Hofmeister Pich do PPG em Filosofia da PUCRS pelas considerações acerca da transcrição do fólio $152 \mathrm{r}$ e das autoridades elencados por Egídio na dicta.

${ }^{24}$ Tradução livre: "Verum est quod aliqui dicunt Christum et apostolos habuisse solum usum, et non dominium eorum que habebant, quod nulla ratione videtur possibile, in his rebus quae consumuntur usu, ut in pane, vino, et pecunia. In istis enim qui habet usum habet omnino dominium: secus est in his quae non consumuntur usu, ut in domo et equo nam in talibus usus potuit a dominio separari”.
} 
Destes significados, interessa o que diz respeito ao poder sobre as coisas, a relação de proprietas. Este tipo de domínio estava relacionado à posse e total controle sobre algum objeto, excluindo os direitos de outra pessoa sobre esse (KILCULLEN, 2011). Apesar de variações, segundo Kilcullen, os teólogos consideravam que dominium e proprietas tinham significados sinônimos. Assim como o uso realizado sem relação de propriedade era considerado como usufruto (KILCULLEN, 2011). Portanto, a solução final apresentada por Egídio pode ser lida da seguinte forma: a propriedade sobre algo é dada pelo domínio que se tem sobre esse objeto, sendo que apenas uma pessoa pode ter domínio sobre algo do qual é detentora do direito de usar a coisa possuída. Caso o bem em questão mantivesse sua substância era possível fazer o usufruto, isto é, o uso sem direito de propriedade; entretanto, isto era inconcebível nos bens consumíveis, uma vez que com o desaparecimento da substância da coisa cessava, também, o direito de propriedade que alguém tinha sobre o objeto, ou seja, consumir algo sem domínio era contrário ao direito.

Ao analisar a dicta do frade João de Nápoles da OP para a comissão de 1322, Patrick Nold demonstra que o frade Pregador responde que Cristo e os apóstolos tinham propriedade comum dos bens e domínio compartilhado sobre os mesmos, uma vez que o uso não poderia ser separado do domínio. Essa é uma linha de raciocínio padrão nas respostas dos frades Pregadores, podendo ser encontrada nas dictae dos frades Hervaeus Natalis e Durando de São Porçiano (NOLD, 2012, p. 647). Conforme Nold, é possível observar diferenças nas considerações de João Nápoles e outros Pregadores, sobretudo, ao considerar que a posse comunal de bens excessiva ou quando envolvia rendas e anuidades poderia afetar a perfeição da vida religiosa (NOLD, 2012, p. 647 e 648). Apesar de não considerar as implicações da posse comum de bens na vida religiosa dos Pregadores, a resposta de Egídio segue a linha de raciocínio: Cristo e os Apóstolos tiveram propriedade comunal sobre coisas por meio da relação de domínio que permitia o uso das mesmas.

\section{Considerações Finais}

Ao longo do texto argumentou-se que é possível a existência de frades Pregadores que defendiam um modelo de vida religiosa semelhante ao dos frades Espirituais da OFM. As regulamentações dos CGs de 1321 e 1327 buscavam coibir um comportamento entre os Pregadores, caracterizados como "singulares na vida". A regulamentação de 1328 e a cláusula penitencial de 1330 abordam sentenças de prisão a alguns frades pelo 
envolvimento com Luís da Baviera, Miguel de Cesena, Pedro de Corbaria e com os Espirituais. Ou seja, as disputas acerca do modelo apostólico de pobreza afetaram a OP, uma vez que os dirigentes expressavam preocupação perante Pregadores associados aos Espirituais. Associação que, também, poderia implicar a escolha e a prática, de uma vida religiosa em que a pobreza era a principal condição para a perfeição. Egídio de Ferrara, ao formular sua resposta para a comissão de 1322, expressa um modelo de pobreza da vida apostólica diferente da pobreza absoluta defendida pelos Espirituais: compreendia a propriedade comunal das coisas assim como o uso e posse de moeda. Para demonstrar que os Apóstolos detinham direitos de propriedade sobre os bens que usavam, Egídio, enfatiza a relação entre pessoa e objeto pelo conceito de domínio. Portanto, a análise da resposta do frade possibilitou encontrar três conceitos como chave para a leitura da documentação administrativa e teológica: pecunia, dominium e proprietas. O próximo passo é comparar a dicta de Egídio com respostas de outros frades Pregadores, cruzando definições sobre esses três conceitos, e com a documentação administrativa da Ordem. 


\section{Referências}

CONSULTA SOBRE A POBREZA DE CRISTO E DOS APÓSTOLOS. Biblioteca Apostólica do Vaticano, Códice Vaticanus latinus 3740, 1322. BAV: Cidade do Vaticano. Disponível em: <https://digi.vatlib.it/view/MSS_Vat.lat.3740>. Acesso em: 16 out. 2019.

FORTES, C. C. Societas studii: a construção da identidade institucional e os estudos entre os frades pregadores no século XIII. Tese (Doutorado), 370 f. UFF/ICHF, 2011. Disponível em: <http://www.historia.uff.br/stricto/td/1344.pdf〉. Acesso em: 14 set. 2019.

GELTNER, G. "Brethren Behaving Badly: A Deviant Approach to Medieval Antifraternalism" In: Speculum, Vol. 85, nº 1, p. 47-64, janeiro de 2010.

HOSTENIUS, L. Codex regularum monasticarum et canonicarum quas ss. patres monachis, canonicis \& virginibus sanctimonialibus servandas prosscripserunt. Ausburgo: Ignatii Adami \& Francisci Antonii Veith, 1759.

KILCULLEN, J. "Medieval Theories of Natural Rights" In: Macquarie University. Sydney, 2011. <https://www.mq.edu.au/about_us/faculties_and_departments/faculty_of_arts/mhpir/staff/s taff-

politics_and_international_relations/john_kilcullen/medieval_theories_of_natural_rights/>. Acesso em: 21 jul. 2019.

LAMBERTINI, R. "Pecunia, possessio, proprietas alle origini di Minori e Predicatori: osservazioni sul filo della terminologia". In: L'ECONOMIA DE CONVENTI DEI FRATI MINORI E PREDICATORI FINO ALLA METÀ DEL TRECENTO (Atti del XXXI Convegno Internazionale della Società Internazionale di studi francescani e del Centro interuniversitário di studi francescani, ottobre 2003). Spoleto: Fundazione centro italiano di studi sull'alto medioevo, p. 5-42, 2004.

MORARD, M.; GIBIINO, F.; e SORBETS, M.-J. (Eds.) Glosa Ordinaria. Paris: Glossae Scripturae Sacrae-Electronicae (Gloss-E), 2016. Sem paginação (Eletrônico). Disponível em: <http://gloss-e.irht.cnrs.fr/php/editions_chapitre.php?livre=../sources/editions/GLOSSliber65.xml\&chapitre=65_4>. Acesso em: 18 set. 2019.

NOLD, P. "How Influential Was Giovanni di Napoli, OP, at the Papal Court in Avignon?". In: EMERY Jr.,K., COURTENAY, W. J. e MATZGER, S. M. (Orgs.) Philosophy and Theology in the Studia of the Religious Orders and at Papal and Rpyal Courts: Acts of the XVth Annual Colloquium of the Société Internationale pour l'Étude de la philosophie Médiévale University of Notre Dame, 8-10 October 2008. Bélgica: Brepols, p. 629-675, 2012.

. Pope John XXII and his Franciscan Cardinal: Bertrand de la Tour and the Apostolic Poverty Controversy. Oxford: Clarendon Press, 2003.

PIRON, S. “Avignon sous Jean XXII, l'Eldorado des théologiens." In: Jean XXII et le Midi, Privat, Cahiers de Fanjeaux, n 45, p. 357-391, 2012. 
REICHERT, B. M. (OP) (Ed.). Monumenta Ordinis Fratrum Praedicatorum Historica: acta capitulorum generalium (vol.II). Roma: Ex Typographia Polyglotta S. C. de Propaganda Fide, 1899. Tomo IV.

SILVA, L. D. "The Franciscan's position and the Marsilius' contribution on poverty debates". In: Thaumazein. Santa Maria, Vol. 8, no 15, p. 75-94, 2015. Disponível em: $<$ https://periodicos.unifra.br/index.php/thaumazein/article/view/568>. Acesso em: 16 jul. 2019.

SPIERS, K. E. "Poverty treatises by Hervaeus Natalis and Pierre Roger (Pope Clement VI) in codex Vaticanus Latinus 4869". In: Manuscripta, n 39, p. 91-109, 1995.

VARGAS, M. A. Taming a Brood of Vipers: Conflict and Change in Fourteenth-Century Dominican Convents. Leiden; Boston: Brill, 2011.

WORDSWORTH, J.; WHITE, H. I. (Eds.) Nouum Testamentum Domini Nostri Iesu Christi Latine: secundum editionem sancti Hieronymi. Londres: E Typographeo Clarendoniano. 
Anexo I - Transcrição da dicta de Egídio de Ferrara (MS BAV, Cod. Vat. lat. 3740 - fl. 152ra-

rb)

[fl. 152ra] Dicta Patriarche Alexandrinis

Ad questionem qua que-

5

ritur utrum asserere $\underline{\text { Christum }}$

et apostolos non habuisse aliquid in communi

sit hereticum. Respondeo ego frater

Egidius Patriarcha Alexandrinus

quod credo hereticum esse. Et ad hoc

10 movent me auctoritates et rati-

ones allegate per Magistrum sacri

palacii, et alios magistros in theo-

logia, aliosque prelatos qui super

hoc coram domino nostro summo ponti-

15 fice sunt locuti precipue me in

ducunt auctoritates evange-

lice et apostolice. Nam Iohannes 4 (:8) circa prin-

cipium sic dicitur: "Discipuli eius

abierant in civitatem ut cibos

emerent". Et Iohannes 13 (:27-29) circa finem:

"Quidam putabant quia loculos ha-

bebat Iudas, et ea que mittebantur

portabat", cum dixisset ei Iesus: "Quيod

facis fac citius", quod dixisset, eme

25 que opus sunt nobị ad dictam festum,

aut ut egenis aliquid daret. Con-

stat autem quod ista non emebantur

de pecunia aliena. Similiter Actus Apostolorum 4 (:32) cir-

ca finem sic dicitur: "Erant illis scilicet apostolis

30

omnia communia", et sequitur (Actus c.4: 34-35) ibidem, neque quisquam

egens erat inter illos. quotquot

enim possessores agrorum aut domorum

erant vendentes, afferebant pecunia

eorum que vendebant et ponebant 
[fl. 152rb] ante pedes apostolorum, dividebant autem

singulis prout cuique opus erat. Que

verba beatus Augustinus per tractaus in regula ${ }^{25}$

ita dicit: Non erat eis aliquid proprium

5

sed erant eis omnia communia. Unde in eodem

capitulo subsequitur (Actus c. 4: 36-37) quod Josep qui cog-

nominatus est Barnabas ab apostolis cum haberet agrum vendidit eum

et attulit precium, et posuit ante pedes apostolorum.

Ad Philippenses ultimo (c. 4:18), Dicebat apostolus: habeo

omnia habundo, dicit glosa ${ }^{26}$ : "habeo

omnia que misistis mihi”. post ascen-

sionem etiam ut dicit Iohannes (c. 21:10-11) ibi evangelio:

"Redierunt ad piscationem et prendi-

derunt 153 magnos pisces $^{27}$, qui

15

cum tenti essent non est fractum

rethe". Constat autem quod filii Zebedei

non comederunt cum sociis omnes pisces

ergo vendiderunt de eis. Verum est

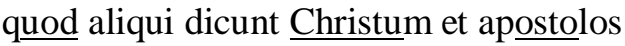

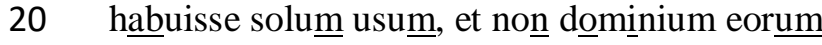

que habebant, quod nulla ratione videtur

possibile, in hiis rebus que consumuntur

usu, ut in pane, vino, et pecunia.

In istis enim qui habet usum habet omnino do-

25

minium: secus est in hiis que non

consumuntur usu, ut in domo et equo

nam in talibus usus potuit a dominio sepa-

rari.

25 Regula Tertia - Praeceptum [Regula ad Servos Dei] de Agostinho de Hippona, Caput II. In: HOSTENIUS, Lucas. Codex regularum monasticarum et canonicarum quas ss. patres monachis, canonicis \& virginibus sanctimonialibus servandas prascripserunt. Ausburgo: Ignatii Adami \& Francisci Antonii Veith, 1759. p. 123.

${ }^{26}$ Glossa Ordinaria. In: MORARD, Martin; GIBIINO, Fabio; e SORBETS, Marie-José (Eds.) Glosa Ordinaria. Op. Cit.

${ }^{27}$ Logo após e um pouco abaixo da palavra "pisces", entre as linhas 14 e 15, há uma intervenção que coloca a palavra "istos". Provavelmente trata-se de uma correção gramatical posterior, provavelmente feita pelo próprio escriba. Agradeço ao professor Dr. Igor Salomão Teixeira pelas considerações quanto a esse ponto. 
Saber Humano, ISSN 2446-6298, V. 9, n. 15, p. 130-150, jul./dez. 2019. 